\title{
Erratum to "Cognitive Rehabilitation for Executive Dysfunction in Parkinson's Disease: Application and Current Directions"
}

\author{
Jessica Calleo, ${ }^{1,2}$ Cristina Burrows, ${ }^{3}$ Harvey Levin, ${ }^{1,4}$ Laura Marsh,, 2 Eugene Lai,, 5 \\ and Michele K. York ${ }^{3,6}$ \\ ${ }^{1}$ Mental Health Care Line, Michael E. DeBakey Veterans Affairs Medical Center, 2002 Holcombe Boulevard, Houston, \\ TX 77030, USA \\ ${ }^{2}$ Department of Psychiatry, Baylor College of Medicine, One Baylor Plaza, 6550 Fannin, Houston, TX 77030, USA \\ ${ }^{3}$ Parkinson's Disease Research Education and Clinical Center, Michael E. DeBakey Veterans Affairs Medical Center, \\ 2002 Holcombe Boulevard, Houston, TX 77030, USA \\ ${ }^{4}$ Department of Physical Medicine and Rehabilitation, Baylor College of Medicine, One Baylor Plaza, 6550 Fannin, Houston, \\ TX 77030, USA \\ ${ }^{5}$ Methodist Neurological Institute, Scurlock Tower No. 802, 6560 Fannin, Houston, TX 77030, USA \\ ${ }^{6}$ Department of Neurology, Baylor College of Medicine, 6550 Fannin, Suite 1801, Houston, \\ TX 77030, USA \\ Correspondence should be addressed to Michele K. York, myork@bcm.edu \\ Received 11 June 2012; Accepted 13 June 2012
}

In this paper which appeared in Parkinson's Disease (2012, Article ID 512892), the reference citation numbers appearing by the authors' names in the left-hand side column did not match the correct references shown and cited. The reference numbers should appear as follows: for Sinforiani et al., the reference number has been changed from [24] to [25], Mohlman et al., the reference number has been changed from [25] to [26], Sammer et al., the reference number has been changed from [26] to [27], París et al., the reference number has been changed from [27] to [28]. 


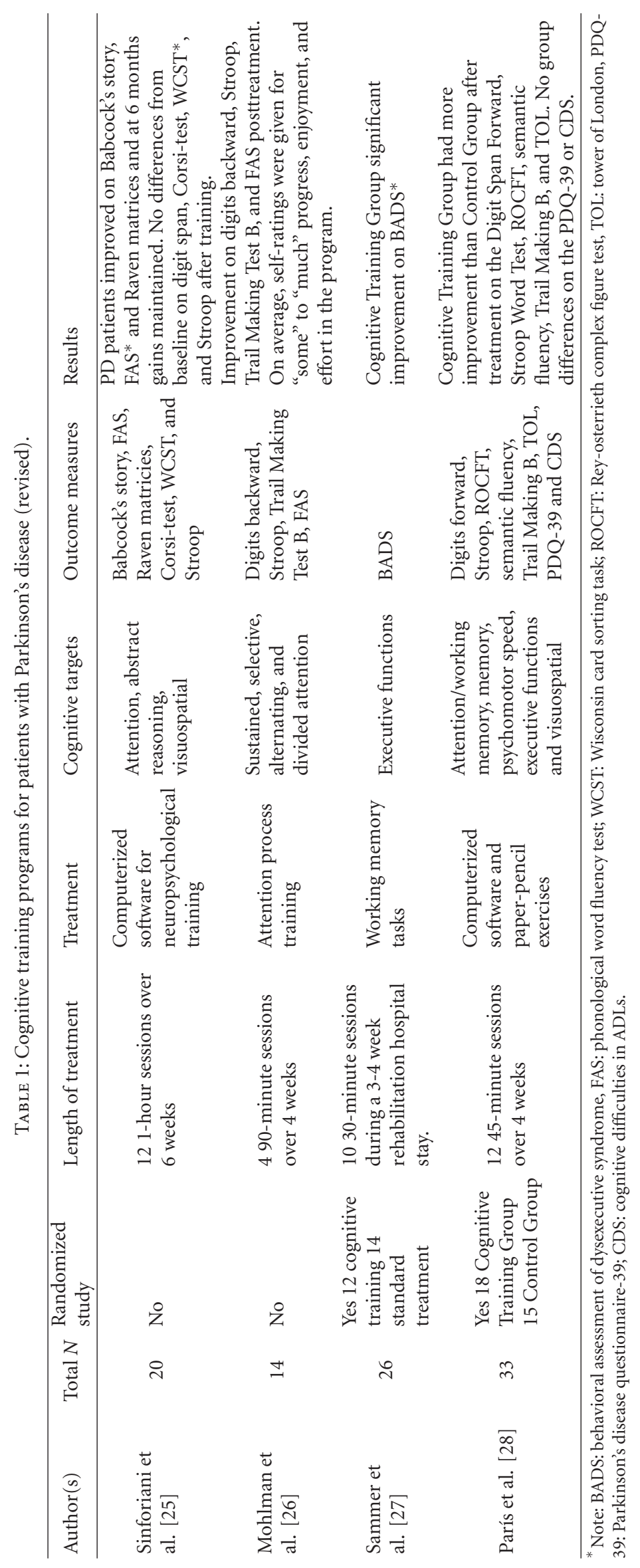




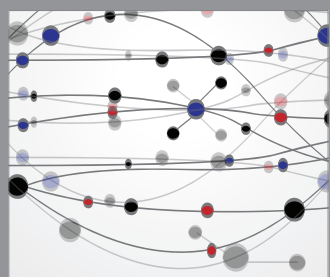

The Scientific World Journal
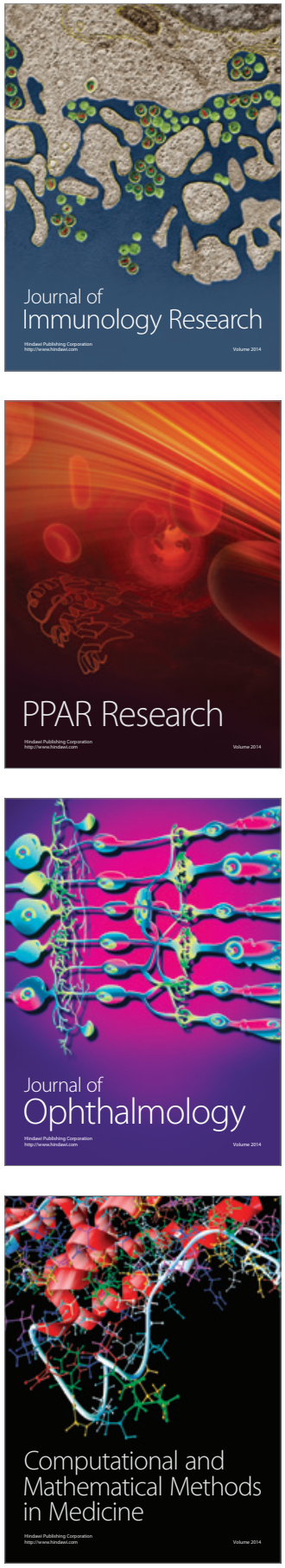

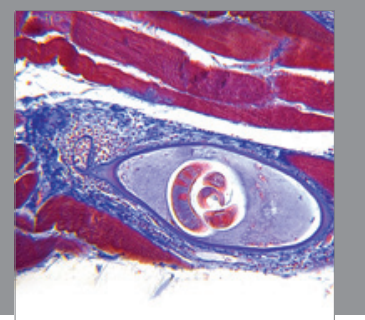

Gastroenterology

Research and Practice
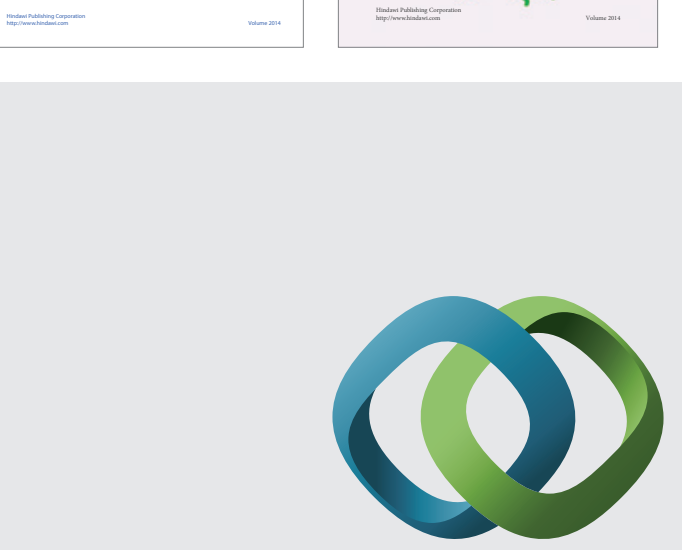

\section{Hindawi}

Submit your manuscripts at

http://www.hindawi.com
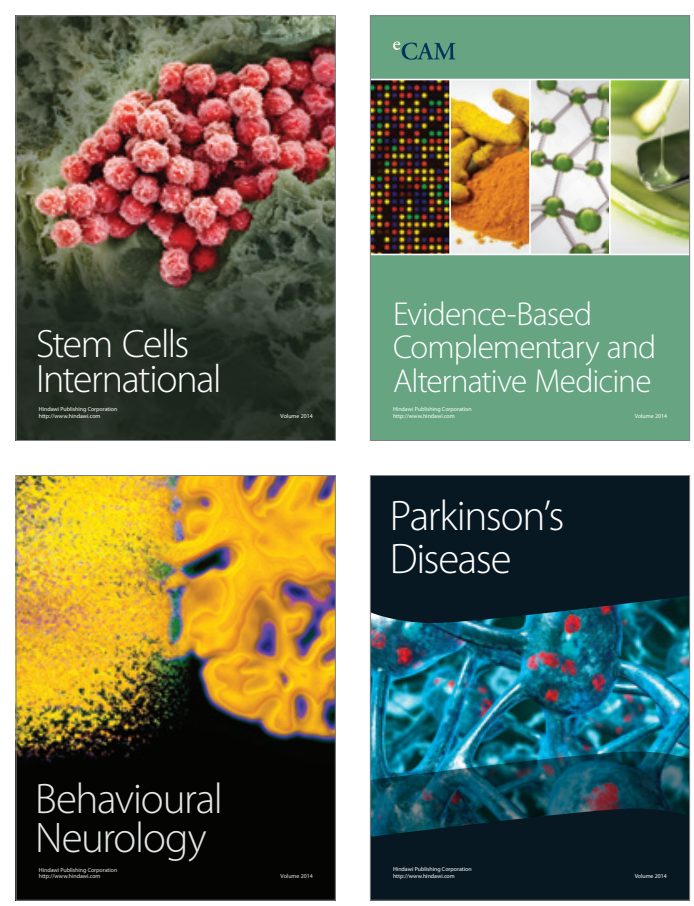

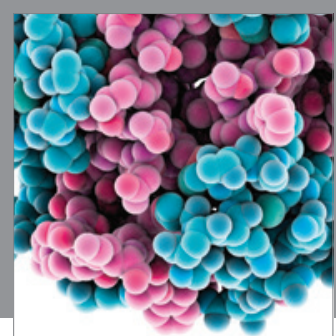

Journal of
Diabetes Research

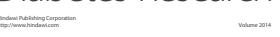

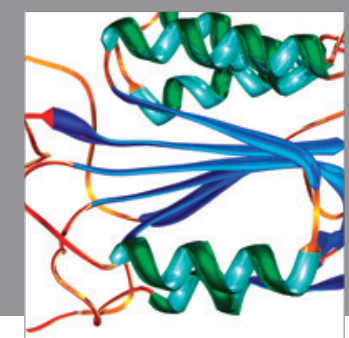

Disease Markers
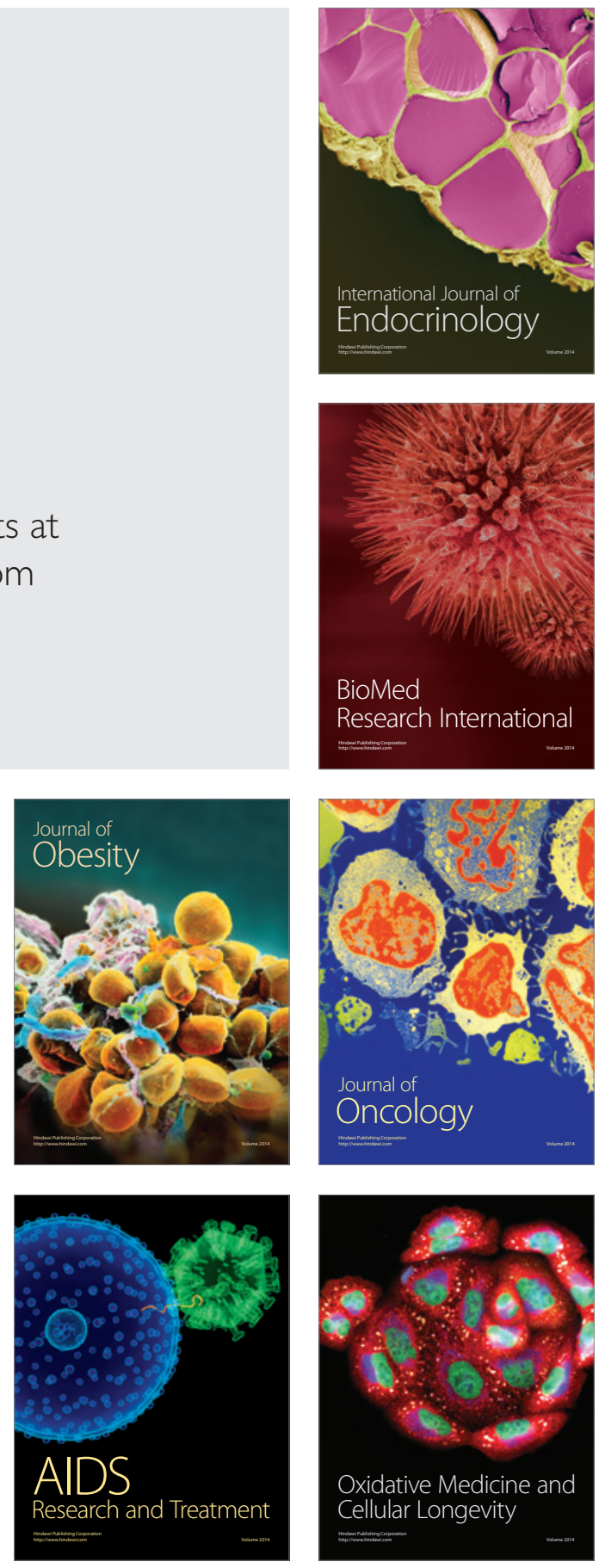